Relations industrielles

Industrial Relations

\title{
Méthode de recherche en droit québécois et canadien, par Denis LelMay, Québec, P.U.L., 1974, 152 pp.
}

\section{Rodrigue Blouin}

Volume 30, numéro 1, 1975

URI : https://id.erudit.org/iderudit/028593ar

DOI : https://doi.org/10.7202/028593ar

Aller au sommaire du numéro

Éditeur(s)

Département des relations industrielles de l'Université Laval

ISSN

0034-379X (imprimé)

1703-8138 (numérique)

Découvrir la revue

Citer ce compte rendu

Blouin, R. (1975). Compte rendu de [Méthode de recherche en droit québécois et canadien, par Denis LeMay, Québec, P.U.L., 1974, 152 pp.] Relations industrielles / Industrial Relations, 30(1), 124-124. https://doi.org/10.7202/028593ar

Tous droits réservés @ Département des relations industrielles de l'Université Laval, 1975
Ce document est protégé par la loi sur le droit d'auteur. L’utilisation des services d'Érudit (y compris la reproduction) est assujettie à sa politique d'utilisation que vous pouvez consulter en ligne.

https://apropos.erudit.org/fr/usagers/politique-dutilisation/ 
deux chapitres, à l'étude des instruments de tradition continentale européenne: I - lois et jurisprudence européennes; II - la doctrine. Tout au long de l'ouvrage les auteurs présentent des commentaires brefs mais très précis.

Tout en insistant sur la haute qualité de l'ouvrage et en invitant les différents intéressés à l'utiliser de façon à assurer une uniformisation des méthodes des références et abréviations qui fait souvent défaut en doctrine québécoise, nous tenons cependant à signaler une légère faiblesse concernant les publications québécoises spécialisées dans les décisions de droit du travail. Ainsi, à la page 55, sous le titre «jurisprudence de droit du travail $\gg$, on ne retrouve que l'abréviation T.Y. On devrait y lire aussi C.E. et S.A.G. Toute une série de modifications doit en conséquence être apportée autant à la liste alphabétique des titres de recueils qu'à celle des abréviations. Pour ne signaler qu'un exemple, l'abréviation T.T. à la page 74 doit se lire «Jurisprudence en droit du travail-Tribunal du travail $\gg$ et non pas seulement «Jurisprudence de droit du travail $»$. Nous rappelons en terminant que cette observation ne doit pas faire perdre de vue l'excellence générale de l'ouvrage.

\section{Université Laval}

\section{Rodrigue BLOUIN}

Méthode de recherche en droit québécois et canadien, par Denis LeMay, Québec, P.U.L., 1974, 152 pp.

Cet ouvrage est essentiellement une initiation à la démarche de recherche documentaire en droit. Son objet fondamental est de rappeler comment peut être trouvé rapidement le matériel nécessaire à la compréhension du droit applicable à un problème, à solutionner: le texte de la loi ou du règlement, les exposés doctrinaux et les décisions jurisprudentielles. Il ne s'agit donc pas réellement d'une méthode de recherche en droit mais seulement d'une étape nécessaire à toute recherche en science humaine, comme l'indique par exemple C. Javeau. D'ailleurs l'auteur lui-même a signalé que son manuel ne se penche que sur la recherche du droit applicable et non sur les autres aspects. Il aurait mieux valu intituler l'ouvrage Méthode de recherche documentaire en droit de façon à situer adéquatement le lecteur.

Dix-sept thèmes sont abordés par l'auteur : quatre thèmes sont consacrés à la vérification des textes législatifs, trois à celle des règlements, trois à la jurisprudence et deux à la doctrine ; un premier thème vise à faire prendre conscience de l'importance de bien qualifier le problème à solutionner; les deux derniers thèmes, qui arrivent comme un cheveu sur la soupe, traitent du Code civil et du Droit municipal.

Dans son ensemble, l'ouvrage reste un excellent document. La construction de la phrase est brève mais précise. L'auteur va droit au but n'exposant que ce qui lui semble essentiel. Occasionnellement, il aurait convenu que des développements plus approfondis soient tentés. Ce n'est cependant que l'utillisation du document qui permettra d'identifier ses insuffisances ou lacunes possibles ainsi que ses aspects les plus positifs.

L'un des aspects les plus intéressants de ce document de travail est qu'il s'adresse à une triple clientèle. Il est avant tout destiné aux étudiants en droit qui, dès le début de leurs études, y trouveront un instrument de travail indispensable à leur formation, un manuel pensé et conçu en fonction des besoins québécois. L'ouvrage pourra aussi servir d'aide mémoire aux praticiens et enseignants de droit. Enfin, et surtout, cette initiation à la recherche documentaire en droit sera d'un précieux secours à une clientèle qui n'est pas de formation juridique mais qui est appelée à se pencher sur les textes législatifs et réglementaires dans leurs activités : fonctionnaires, professeurs et praticiens en relations du travail, administrateurs, et autres.

En définitive, on ne peut que conseiller aux différents intéressés à la recherche documentaire la lecture de l'ouvrage de M. Denis LeMay. A cet effet, les suggestions faites par l'auteur pour une valorisation de la documentation juridique (épilogues I et II) ne manqueront pas de susciter chez eux des réactions le plus souvent positives. Il suffira de consulter la Méthode de recherche en droit québécois et canadien pour savoir de quoi il en retourne.

Université Laval
Rodrigue BLOUIN 